\title{
e-HEALTH SUPPORT PROMOTES DIETARY IMPROVEMENTS IN WOMEN PREVIOUSLY TREATED FOR CANCER: RESULTS FROM THE AUSTRALIAN WOMEN'S WELLNESS AFTER CANCER PROGRAM
}

\section{E. Agarwal ${ }^{1}$, C. Seib 2 , J. Porter-Steele ${ }^{3}$, A. McGuire2, S. Balaam4, E. Harbeck ${ }^{2}$, A. McCarthy5 , D. Anderson².}

${ }^{1}$ Bond University, Master of Nutrition \& Dietetic Practice Program, Gold Coast, Australia.

${ }^{2}$ Griffith University, Menzies Health Institute Queensland and School of Nursing and Midwifery, Gold Coast, Australia.

${ }^{3}$ The Wesley Hospital, Choices Program, Auchenflower, Australia.

${ }^{4}$ Queensland University of Technology, Australia Institute of Health and Biomedical Innovation and School of Nursing, Kelvin Grove, Australia.

${ }^{5}$ University of Auckland, School of Nursing, Auckland, New Zealand.

\section{Introduction}

Survivors of breast, gynaecologica and blood cancer are at an increased risk of chronic disease, particularly if dietary choices are poor.

We examined the efficacy of an e-health lifestyle program on compliance with World Cancel Research Fund (WCRF) and American Institute for Cancer Research (AICR) dietary guidelines in women after cancer.

\section{Methods}

351 Australian women were randomised into control group or intervention group.

The intervention group received a 12 week structured lifestyle intervention, the Women's Wellness after Cancer Program (WWACP).

Both groups completed Food Frequency Questionnaires at three time-points (baseline, 12 weeks, and 24 weeks).

Generalized Estimating Equations (GEE) were used to examine changes in dietary patterns both within- and between- groups over the study period.

\section{Results}

Both groups were comparable at baseline for age, education, employment and income, or dietary choices ( $p>0.05)$.

Over the study period changes in dietary patterns were noted with a reduction in daily consumption of energy-dense foods and red meat across the cohort $(p<0.05)$.

GEE also showed that among the intervention group, there was a significant increase in total daily serves of fruit and vegetables and a significant decrease in waist-to-hip ratio over time $(p<0.05)$.

\section{Conclusion}

Conclusion of active treatment provides an unmissable window of opportunity for education and support for positive dietary changes targeting potential chronic disease risk factors.

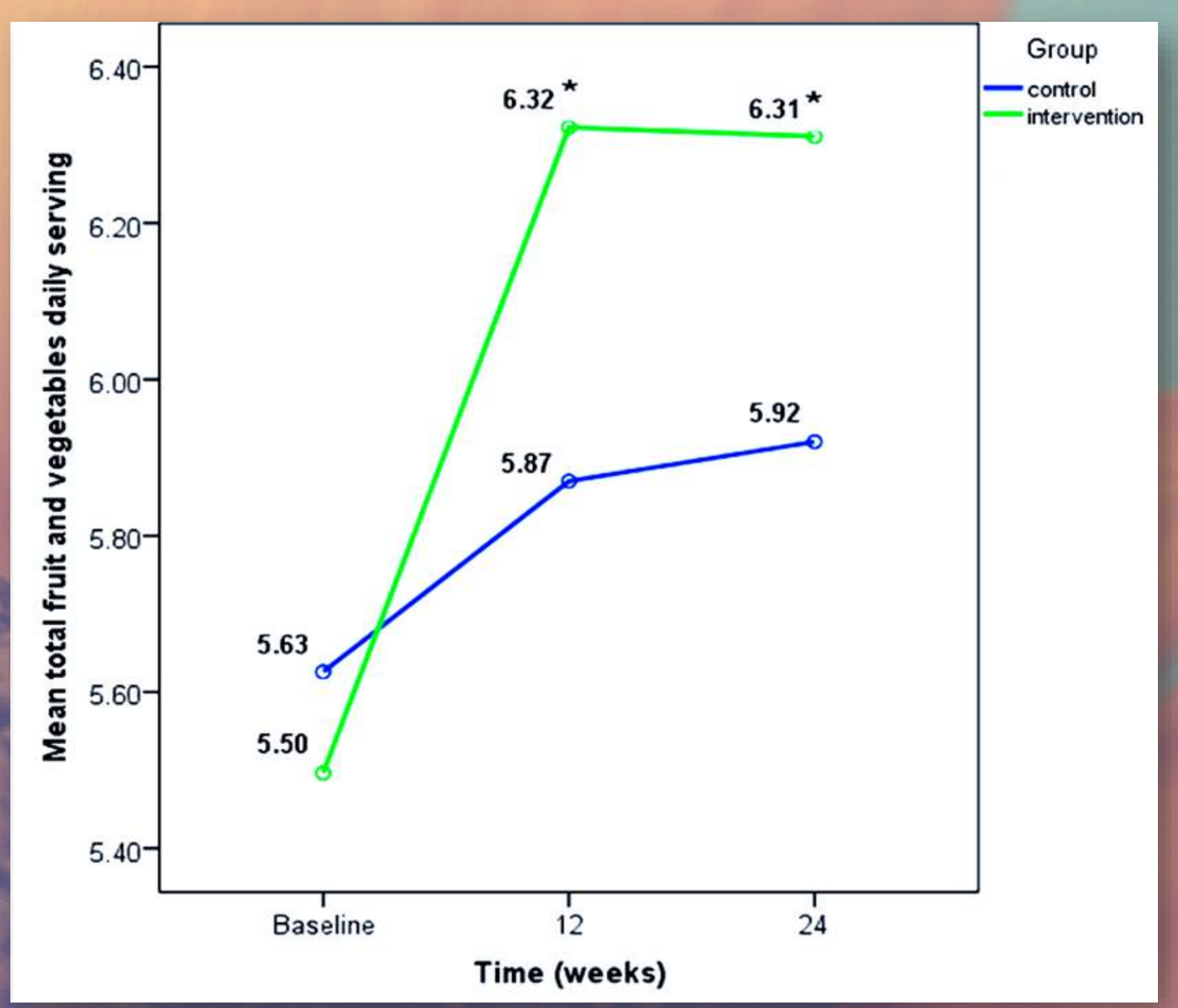

